Anuario de la Facultad de Derecho. Universidad de Extremadura 35 (2019): 533-569 ISSN: 0213-988X - ISSN-e: 2695-7728

\title{
PERFORMATIVIDAD Y NOMINALISMO EN LA FILOSOFÍA POLÍTICA DE BUTLER: NUEVAS VERSIONES DE UN VIEJO PROBLEMA
}

\section{PERFORMATIVITY AND NOMINALISM IN BUTLER'S PO- LITICAL 'PHILOSOPHY: NEW VERSIONS OF AN OLD PROBLEM}

\author{
JosÉ LUIS MUÑOZ DE BAENA \\ Universidad Nacional de Educación a Distancia
}

Recibido: 05/07/2019 Aceptado: 18/09/2019

\section{RESUMEN}

El texto cuestiona radicalmente la continuidad entre el marxismo y la filosofía política queer, y lo hace desde un análisis de las bases epistemológicas (nominalistas) de esta última, condensadas en la performatividad del sexo. El escepticismo sobre la posibilidad de los conceptos universales conduce a negar todo discurso centrado en dualidades (naturaleza-cultura, masculino-femenino, público-privado, objetivo-subjetivo...), lo que significa impugnar cualquier propósito emancipador, al privarlo de sus herramientas teóricas. Lo queer reduce el panorama de lo político a un escenario de sujetos escindidos, capaces de articularse circunstancialmente pero no de comprender lo que los une: quedan reducidos a sus identidades, siempre mudables porque son una suma de diferencias. Por último, se busca un planteamiento de estas cuestiones que supere las aporías de lo queer mediante un planteamiento hermenéutico.

Palabras clave: Performatividad, nominalismo, Butler, identidad. 
The text radically questions the continuity between Marxism and Queer political philosophy, and it does so from an analysis of the epistemological bases nominalists of the latter, condensed in the performativity of sex. Skepticism about the possibility of universal concepts leads to denying any discourse centered on dualities (nature-culture, masculine-feminine, public-private, objective-subjective ...), which means denying any emancipatory purpose, by depriving it of its theoretical tools.Queer political philosophy reduces the political landscape to a scenario of split subjects, capable of articulating circumstantially but not understanding what unites them: they are reduced to their identities, always changeable because they are a sum of differences. Finally, an approach to these issues is sought that overcomes the aporia of queer through a hermeneutical approach.

Keywords: Performativity, nominalism, Butler, identity.

Sumario: 1. Introducción. 2. La autonomía de lo cultural. 3. La persistencia de la justicia distributiva. 4. La indisponibilidad del sexo. 5. Los problemas teóricos de lo queer: el uso y abuso de los performativos y la constitución lingüística de la identidad. 6. Una salida hermenéutica de las aporías de lo queer.

\section{INTRODUCCIÓN*}

No es aventurado sostener que la sorprendente inanidad de la izquierda postmoderna actual, a pesar de tener como adversario a un sistema de capitalismo financiero insostenible, es tributaria de su desconexión de los problemas reales y su empecinamiento en la certeza de que las palabras crean cosas; o, dicho de otro modo, en su rechazo total a todo problema ontológico, acaso la parte más reductora de su herencia foucaultiana. Ello la ha conducido al intento de apurar todos los post posibles: postestructuralismo, postcolonialismo, postfundacionalismo y, resumiéndolos a todos, postmodernismo. En el extremo -y el extremo es, a mi entender, el feminismo de Butler-, podemos resumir

\footnotetext{
* Agradezco profundamente a mi amiga y compañera Carmen Huici, catedrática de Psicología Social en mi universidad, la inestimable ayuda que me ha prestado en la búsqueda de la bibliografía científica relativa al dimorfismo sexual.
} 
este movimiento teórico en dos aspectos conexos: la negación de cualquier tipo de evidencia de carácter no cultural y la reducción de lo real a lo lingüístico. El resultado es, a mi entender, una desarticulación radical de los ideales emancipatorios, a los que se considera, en la actual situación de la teoría social, imposibles de reducir a la unidad (como si ese ejercicio de univocismo fuese la clave de la solución) ${ }^{1}$; además, dada la total liberación -dilución más bien- de los significantes, cada lenguaje emancipatorio es susceptible de contar un relato, eventualmente en conflicto con los otros mini o microrrelatos, envuelto en derechos subjetivos reales o imaginarios, en una fragmentación de lo político, de lo común, que tiende dramáticamente a lo fractal. No resulta extraño que últimamente se hayan multiplicado las voces que denuncian, tras el culto a la diversidad, una suerte de maniobra de diversión del sistema, al cual nada amenaza ya seriamente (Bernabé 2018). Tampoco puede extrañar que los partidos socialdemócratas de tercera vía sean entusiastas defensores de las llamadas políticas de profundización en los derechos, centradas casi exclusivamente en el enfoque LGTBIQ+, ya que su propia condición de reformistas mantenedores del sistema económico los hace propensos a utilizar las vindicaciones identitarias como una mercancía electoral fácil de capitalizar².

Lo anticiparé con la radicalidad que requiere: estimo que la dilución de todo contenido político sustancial en lo simbólico-cultural es, además de una traición a la izquierda política, un suicidio. Y el arma humeante no es sino el viejo nominalismo filosófico al que hoy resulta innecesario mencionar por su nombre, porque el rechazo casi omnipre-

1 "La historia del sujeto es la historia de sus identificaciones, y no hay una identidad oculta que deba ser rescatada más allá de la última identificación (...) ningún centro de subjetividad precede a las identificaciones del sujeto" (Mouffe 1996, 3).

2 Acaso el ejemplo más señalado sea el del primer mandato de Rodríguez Zapatero, que disfrazó eficazmente sus políticas neoliberales (continuación en lo esencial del boom inmobiliario, devolución de cuatrocientos euros a todos los ciudadanos, supresión del impuesto sobre el patrimonio...) gracias a dicha profundización en los derechos, que presentaba la ventaja de su escaso coste presupuestario. Las medidas con un carácter más genuinamente emancipador, como las relativas al cambio de modelo energético o a la atención remunerada a la dependencia, carecían de soporte presupuestario adecuado y no necesitaban el feroz ataque de que fueron objeto por parte de la derecha para convertirse en poco más que brindis al sol. 
sente de cualquier visión coherente e integrada de lo real lo impone por doquier. Como dijo Borges, la victoria del nominalismo es tan amplia, que su nombre es ya inútil: nadie se llama nominalista porque nadie hay que sea algo diferente.

Esa renuncia a adscribir a los términos tradicionales de la teoría social y la teoría de la justicia un significado estable y operativo (incluso por la tímida vía de lo procedimental, al modo de Rawls) ha dinamitado cualquier intento serio de rehabilitar el viejo concepto de justicia distributiva, puesto que la redistribución está dejando paso al reconocimiento como vindicación crucial de las sedicentes izquierdas. Los términos en que la propia Butler enunció el problema, hace ya más de veinte años, reconocían que era frecuente la certeza de que el postestructuralismo había bloqueado al marxismo, operando como "...una corriente destructiva, relativista y políticamente paralizante” y generando una “...imposibilidad de ofrecer explicaciones sistemáticas de la vida social o de sostener normas de racionalidad, ya sean objetivas, universales o de ambos tipos" (Butler 2016, 68).

\section{LA AUTONOMÍA DE LO CULTURAL}

Ciertamente, Butler, como buena representante de esa filosofía de la sospecha que permea los estudios culturales, hace bien en desconfiar de un constructo como el de clase social, empeño en el que está acompañada de multitud de pensadores próximos al postestructuralismo; entre ellos, cabría destacar a Laclau y Mouffe. El argumento es bien conocido: no deberíamos presuponer que la diferencia entre lo material y lo cultural es clara y terminante. Quienes lo dan por establecido, no pretenden otra cosa que “...restablecer lo universal por decreto, ya sea empleando la precisión imaginaria de la racionalidad habermasiana o mediante las concepciones del bien común que priorizan un concepto de clase racialmente neutro" (Butler 2016, 73); en un sentido similar se 
manifiesta Mouffe (Mouffe 1996, 12), que considera a toda noción sustantiva del bien común incompatible con la moderna democracia3. Quizá, por cierto, deberíamos preguntarnos si la teoría social de los últimos treinta años no ha pretendido más bien lo contrario: disolver lo universal en lo particular por decreto, incluyendo el concepto de bien común, debido al desplazamiento desde una teoría centrada en la distribución a otra basada en el reconocimiento.

El problema, a mi entender, no es que la pensadora estadounidense se instale en ese recelo hacia el universalismo (el pensamiento solo avanza recelando), pues resulta indudable que sostener algo así como la unidad de la clase obrera en nuestros tiempos no es posible sin muchas precisiones. Tampoco, a mi entender, radica en su feminismo, pues este movimiento se ha mostrado tan capaz de conseguir grandes transformaciones sociales, que sería difícil discutir su carácter emancipatorio; de hecho, Butler ha reprochado a sus críticos que, al censurar la doctrina queer, atacan precisamente a la parte más activa de la izquierda (Butler 2016, 73). Pero no sé si esto es un argumento solvente, al menos si aún nos importa el qué de una actividad frente al cómo.

El problema es otro: al situar el discurso de la emancipación sobre fundamentos totalmente inestables (la aspiración, no ya a una tenue e imprecisa identidad colectiva, sino al reconocimiento de cada identidad, sin más base que la autopercepción), la filosofía política centrada en lo queer impide una teoría de la justicia digna de ese nombre. Pues una tal teoría ha de tomar posición con respecto a algo tan comprometido como los criterios del reparto: posición económica, trabajo, necesidades... Y eso supone, por más que se particularice cada situación, partir de la posibilidad, de la necesidad, de un lenguaje común capaz de hacer valer categorías universales (la justicia lo es, por más que se aplique a cada caso concreto de un modo diferente), lo que resulta contradictorio con

3 Con todo, cabe preguntarse si hay una consideración del bien común que no sea sustantiva. 
una posición teórica como la de Butler4. Es concebible que una mayoría de la población oprimida pueda apoyar una doctrina como la queer sin renunciar a los ideales universalistas de las izquierdas, pero situar aquella en el núcleo mismo de la lucha política supone, sin demérito de sus vindicaciones, instalar el sentido de las izquierdas en lo accidental y no en lo esencial, como luego veremos. Y ello hace difícil la compatibilidad con otros movimientos emancipatorios, siquiera bajo la cobertura, tan postmoderna, de la articulación. En el límite, la teoría (anti)política queer acaba con todo discurso posible sobre la justicia, pues no establece más que un criterio normativo de igualdad: el derecho a ejercer la propia diferencia. Luego mostraré que esto constituye un problema tanto estratégico como teórico.

Butler planteaba ya esta cuestión en su célebre polémica con Fraser hace casi un cuarto de siglo, incapaz de asumir el problema: sin dejar de reconocer que el identitarismo estrecha el campo político, afirmaba a la vez que la unidad en la vindicación “...no debería erigirse sobre la síntesis de un conjunto de conflictos, sino que habría de constituirse como una manera de mantener el conflicto de modos políticamente productivos, como una práctica contestataria que precisa que estos movimientos articulen sus objetivos bajo la presión ejercida por los otros, sin que esto signifique exactamente transformarse en los otros" (Butler 2016, 73).

El temor a la síntesis es más que comprensible en una perspectiva post, pero es que no es necesaria una síntesis (tampoco, por cierto, una

\footnotetext{
4 El modo en que Butler se refiere a este concepto es comprensible en quien, como Foucault, ha llevado su nominalismo hasta el límite, negando casi cualquier núcleo normativo, cualquier criterio material de justicia más allá del propio cuerpo: lo común, so capa de rehuir todo idealismo, se disuelve en individualidades autorreferentes y lo social aparece evanescente, como un milieu que siempre está en segundo plano: “...cuando los cuerpos se reúnen con el fin de expresar su indignación y representar su existencia plural en el espacio público, están planteando a la vez demandas más amplias: estos cuerpos solicitan que se los reconozca, que se los valore, al tiempo que ejercen su derecho a la aparición, su libertad, y reclaman una vida vivible (...) el «yo» es al mismo tiempo un «nosotros», al que no se ha tenido que fusionar en una unidad imposible (...) lo individual, aun cuando sea autorreferencial en un grado elevado, está aludiendo siempre a sí mismo a través de una forma mediadora, a través de los medios, y el propio lenguaje con el que se reconoce a sí mismo viene de otro lugar" (Butler 2017, 33, 58, 215).
} 
jerarquización): la unidad proviene, a mi entender, de la posibilidad de cruzar las vindicaciones por un denominador común coherente que vaya más allá del mero “¿qué hay de lo mío?”. Y eso supone, me temo, el recurso a la justicia que Butler invoca, a la vez que la problematiza de continuo, y al bien común que, como todos los autores postmodernos, denuesta; un rechazo que comparte, dicho sea de paso, con los neoliberales, tan instalados como ella en un modelo social de identitarismo atomizador, bien que de fundamento muy diferente. No se ve bien qué podría articular una protesta generalizada que no fuese común; tampoco es fácil imaginar qué podría defenderse como común que no fuese un bien, o que no se percibiese como tal5.

Una de las cuestiones cruciales es -y tanto Butler como Fraser lo vieron claro en su polémica- si el problema es de naturaleza estratégica o teórica. Declinado de antemano el intento de producir una teoría social capaz de albergar lo diverso y concebirlo de modo unitario -no en vano el postfundacionalismo rechaza todo fundamento necesario de lo político-, el problema se acerca, me parece, más a lo estratégico que a lo teórico: cómo unir lo que la teoría social ha separado previamente. El problema, para los post en general, no puede ser teórico porque han renunciado a la teoría, en sentido fuerte. Pensemos en la articulación a la que se refiere Mouffe: una mera yuxtaposición o coordinación de vindicaciones, a las que nada une trascendentalmente porque los criterios para postular una tal unión han sido meticulosamente despedazados... como lo ha sido todo aquello que permite -Foucault dixit- ejercer el juego consolador de los reconocimientos.

5 La reducción del bien común a pretensiones inconmensurables que lo refutan es un fenómeno típicamente liberal. Pensemos en uno de los padres del neoconservadurismo, I. Kristol, partidario de un nacionalismo sin complejos y del mantenimiento del imperialismo militar de los EE.UU., de quien se recuerda alguna frase comparando el reconocimiento de la homosexualidad con la pornografía. En Neoconservatism, podemos leer: “...the liberty of a liberal society derives from a prevalent skepticism as to anyone's ability to know the 'common good' with certainly, and from the conviction that the authorities should not try to define this 'common good' in any but a minimal way" (Kristol 1995). 
Creo que, si examinamos el rumbo de las concepciones políticas de la Modernidad, el motivo de esta limitación aparecerá con cierta claridad: se trata de concebir del modo más articulado y operativo posible -esto es, en términos estratégicamente viables- un todo que es solo la suma de sus partes, porque nada lo cruza en su integridad. Ese es el sentido de la teoría política hobbesiana y, en general, de los modelos contractualistas. Se trata, desde luego, del problema epistemológico basal de toda teoría política liberal: los sujetos son concebidos como entidades discretas -o posiciones determinadas, en términos postmodernos- a las que nada une necesariamente, pues solo el discurso del poder los articula de modo precario. La ausencia de universales con fundamento real tiende a la disolución de todo vínculo social, lo que impone la necesidad de buscar principios unitivos, siempre provisionales, siempre desechables. La Modernidad los produjo por doquier: una naturaleza vicaria (Locke), una personalidad moral (Pufendorf), una voluntad colectiva (Rousseau), una eticidad (Hegel), una autolimitación estatal (Jellinek), una clase social oprimida (Marx), una fusión de lo político en lo jurídico (Kelsen). Por eso lo que caracteriza al pensamiento moderno, pese a su enorme diversidad, es que se instala en la categoría de lo posible. La ya larga historia de la Modernidad consiste en eso: en superar la tendencia a la disolución del cuerpo social ínsita en su posición inicial nominalista, y en hacerlo mediante formas ad hoc, cada vez más tendentes a consagrar el predominio del Estado y el sistema y llamadas, como sostuvo Adorno en su Dialéctica negativa, a ser sustituidas cada una por la siguiente. En este punto, nada separa a la era moderna de la postmoderna, salvo en que la primera veía un sentido en la pretensión de buscar solución a esa tendencia mediante los referidos principios unitivos (Muñoz de Baena 2018). Como es sabido, tras Foucault y Lyotard quiebra la posibilidad de invocar principios capaces de organizar lo social y político en estructuras binarias (naturaleza-cultura, público-privado, derecho objetivo-derecho subjetivo $)^{6}$. Y la Modernidad

6 A propósito de Butler, M. A. Campagnoli lo resume muy precisamente: "Tradicionalmente la 
retorna, tras su crisis a mediados del XX, al patrón nominalista que la alumbró cuatro siglos antes, tras lo cual no resta sino un continuo agitarse de vindicaciones mutuamente inconmensurables y no reducibles, al contrario que las modernas, a un sujeto histórico privilegiado (el proletariado, si nos mantenemos en el ámbito de la teoría emancipatoria tradicional). Persiste la categoría fundamental, exacerbada hasta el límite: lo posible frente a lo actual, en sentido aristotélico. Solo que ya no hay límites para esa posibilidad, ni siquiera el de lo real, pues la realidad se considera el producto de una imputación lingüística. Más adelante veremos hasta qué punto.

Aquí es donde las teorías post están llamadas a quebrar y hacer imposibles los precarios fundamentos de las teorías políticas modernas con su énfasis en lo cultural, ya muy evidente en Althusser7. Los mundos simbólicos son irreductibles y su presencia (su omnipresencia) hace saltar la estricta correspondencia entre ideología y clase social del marxismo clásico.

\section{LA PERSISTENCIA DE LA JUSTICIA DISTRIBUTIVA}

Pese a ello, el viejo discurso sobre la justicia no ha desaparecido de la teoría feminista. De hecho, una feminista de izquierdas plenamente coherente con ambas condiciones, como Nancy Fraser, puso de manifiesto, en su polémica con Butler, que una teoría feminista coherente no puede dejar que el reconocimiento ahogue a la distribución. La autora, que pese a su asunción de muchos de los postulados post no olvida la esencia del ideal emancipatorio, lo deja bien claro: el problema son las

\footnotetext{
'justicia' como valor ético eminente se sostiene merced al privilegio del ámbito público, que conlleva a su vez la previa exclusión del ámbito de lo privado personal con los valores que le son asociados: cuidado, nutrición, afectividad, solidaridad, interrelación, como irrelevantes para la ética. De este modo, la jerarquía Justicia/Cuidado se encabalga sobre las correspondientes Público/Privado, Cultura /Naturaleza, Masculino/Femenino. Entendemos estas jerarquías como resultado de complejas construcciones sociopolíticas" (Campagnoli 2015, 255).

7 Un énfasis ya anticipado en Gramsci y en los frankfurtianos. Precisamente es Althusser el pensador que Butler utiliza para negar la cesura entre lo material y lo cultural.
} 
circunstancias en que la política del reconocimiento puede contribuir a la de la redistribución, lo cual la lleva a preguntarse: “¿Cuál de las muchas variantes de la política de la identidad entra mejor en sinergia con las luchas por la igualdad social? ¿Y cuáles tienden a interferir con estas últimas?” (Fraser 2016, 25).

La pretensión de Fraser de elaborar una crítica de la redistribución es sensata; su convicción de que la falta de reconocimiento es real y no meramente cultural resulta también muy acertada. Con todo, encuentro cuestionable su intento de mantener distribución y reconocimiento en un cierto equilibrio, aún más, de afirmar que la ausencia de este último es tan contraria a una participación igualitaria como las desigualdades distributivas (Fraser 2000, 126). Pues la redistribución, por su referencia esencial al reparto de bienes y cargas en una sociedad, es la categoría basal y más comprensiva. No hace falta ser materialista para suscribir el primum vivere que ya enunciaron los romanos; no creo que se pueda obviar que la justicia tiene como fondo a los bienes básicos antes que a los derechos, dado el carácter tercamente tangible de aquellos; habría, en fin, que estar muy poco reconciliado con lo real para ignorar que la consecución de lo que nos permite mantener la vida es lógicamente anterior a cuanto puede ayudarnos a disfrutarla ${ }^{8}$. Con todo, si tenemos en cuenta la deriva que ha sufrido el concepto de materialidad con el pensamiento post, como luego veremos, no puede extrañar que se equipare falta de reconocimiento con ausencia de bienes básicos.

Si algo muestra esto, es que la escisión entre reconocimiento y distribución se mantiene hoy como una de las cuestiones fundamentales en la teoría feminista; un conflicto que no aparece en la gran adalid del feminismo de izquierdas de los setenta y ochenta, Angela Davis. Esta autora marxista sin complejos, a quien se puede considerar modélica

8 No otra evidencia tenía delante Rawls, el máximo teórico de la redistribución en el siglo XX, cuando intentó elaborar una teoría de la justicia que no quedase en flatus vocis; y lo hizo en contra, precisamente, de los liberales radicales que pretendían reducir lo político a un reconocimiento de las identidades individuales, como si estas fuesen anteriores a los bienes. Algo, me temo, muy similar a lo que pretende Butler, aunque con propósitos diferentes. 
tanto por su teorización como por su valiente enfrentamiento al sistema, vincula raza negra, sexo femenino y clase social baja de un modo inescindible (resulta chocante que hoy en día, la viabilidad discursiva del segundo de los conceptos esté siendo cuestionada, precisamente, por las feministas queer), pero no deja de tener claro que los tres modos de opresión nacen de la injusticia en el reparto de los bienes ${ }^{9}$. En este mismo sentido, Frank Lilla ha recordado, muy recientemente, que el gran movimiento de los derechos civiles nacido en los sesenta fue la plantilla para garantizar los derechos identitarios: mujeres, homosexuales, etc. (Lilla 2018, 74). Desde luego, no al revés.

En cualquier caso, si algo resulta evidente en la polémica es hasta qué punto los discursos sobre la identidad y el reconocimiento se han hecho -artificialmente- antitéticos en la teoría queer; escisión que se debe, estimo, a una deficiente interpretación por algunas de sus defensoras de las bases filosóficas de la Modernidad. Un ejemplo lo mostrará adecuadamente: el argumentario de Fraser frente a Butler, la importancia que concede a las teorías neohegelianas del reconocimiento (Taylor, Honneth), consideradas como de carácter ético y, por tanto, centradas en el concepto de vida buena frente a las teorías morales del procedimentalismo kantiano, demuestra ciertamente su buen conocimiento de la filosofía moral contemporánea y su capacidad para enfocar el problema fundamental, esto es, que la pretensión de reconocimiento “...implica la tesis hegeliana, considerada a menudo opuesta al individualismo liberal, de que las relaciones sociales son anteriores a los individuos y la intersubjetividad es anterior a la subjetividad" (Fraser 2008, $85)^{10}$. Pero no ayuda a clarificar la cuestión de los fundamentos teóricos del reconocimiento, ya que se mantiene dentro de los postulados (según

9 “...siempre he insistido en la prioridad de la práctica radical por encima de la identidad pura y simple. Importa más qué haces para facilitar la transformación radical que cómo te imaginas que eres. Y, claro, como ya he indicado, las categorías de género y raza, al igual que la sexualidad y la clase, sólo son significativas dentro de unas interrelaciones más complejas" (Colera 2016).

10 "....a diferencia de la redistribución, suele interpretarse que el reconocimiento pertenece a la "ética", en cuanto opuesta a la "moral", es decir, que promueve los fines fundamentales de la autorrealización y la vida buena, frente al "derecho" de la justicia procedimental”. 
Butler, dualistas y esencialistas) de la Modernidad. Por cierto, la vida buena es un concepto anterior en más de dos milenios a Hegel; una aspiración de raigambre aristotélica, reactivada por el comunitarismo. Y podemos ver, sin duda, el reconocimiento en clave de vida buena, no otra cosa hacen los comunitaristas, pero no existe una vida buena en interpretación post, pues ese concepto supone una opción por lo materialmente bueno, concebido en términos intersubjetivos, que resulta imposible de conciliar con el constructivismo extremo de Butler y su cuestionamiento de cualquier universal ${ }^{11}$. Si hemos de polemizar sobre Butler, nada de esto sirve ${ }^{12}$.

Por eso debo volver a mi argumentación: el problema no es, creo, lo que la teoría de Butler tiene de feminista radical (Davis y Fraser también lo son), sino lo que tiene de postmoderna, esto es, basada en una concepción del lenguaje que lo hace perennemente disponible por la voluntad, con el resultado de enervar cualquier pretensión universalista. Veamos esto con cierto detalle.

\section{LA INDISPONIBILIDAD DEL SEXO}

Difícilmente podremos dejar de ver esta característica en su concepción del sexo, al que considera una construcción cultural; creo que es en este punto, central en su filosofía, donde más claramente la autora estadounidense hace imposible un discurso articulado sobre lo justo.

\footnotetext{
11 Yendo al extremo opuesto, tampoco podremos asociar sin más lo moral-procedimental (Rawls) con la redistribución, pues ello supondría obviar, por ejemplo, a la filosofía política republicana (Pettit, Barber), que es tan redistributiva como ética, y que vindica tanto el concepto de vida buena como el de bien común.

12 Butler trata la cuestión de la vida buena, a mi entender, de un modo equivocado, al separarla totalmente de toda cuestión moral sustantiva (lo que, por otra parte, es comprensible en ella): “...quienes no llevan una buena vida pueden estar disfrutando también del bienestar material y de la seguridad. Y esto es aún más claro en el caso de quienes disfrutan de una buena vida gracias a la explotación del trabajo de los demás o del aprovechamiento de un sistema económico que afianza algunas formas de desigualdad" (Butler 2017, 196). Ni unos ni otros llevan una vida buena ni una buena vida: a lo más, viven bien.
} 
Cualquier profesional de la antropología aceptaría sin reservas que el género es una construcción cultural, producida a partir de la existencia de excedentes, y que su función es la de no asociar inexorablemente una cierta configuración genital y fisiológica a un determinado rol$^{13}$. Pero la atribución de un rol (un género) a un sexo determinado es lo máximo que podemos introducir de cultural en esta cuestión. Y no es poco. La biología, la fisiología, han dispuesto de millones de años para determinar un modo de reproducción basado inexorablemente en la distinción sexual. Podemos alojar el óvulo en un tubo de ensayo, quizá algún día podamos conseguir que se desarrolle en el interior de un varón -si es que eso tiene algún sentido-, pero no nos es posible prescindir de un espermatozoo y un ovocito. En este aspecto, los humanos estamos sujetos a nuestra diferenciación por sexos (no géneros), debido a un encadenamiento de cuatro evidencias enojosamente imposibles de obviar: la pervivencia de la especie equivale a la reproducción; no existe reproducción sin mezcla de células reproductoras; esa mezcla requiere una dualidad de sexos (sexos, no géneros); dicha dualidad no es obviable, solo ligeramente moldeable por la cultura.

Cuestión diferente es que el avance de la cultura y de la tecnología permita a ciertos sujetos liberarse de la tensión que supone asumir inexorablemente la carga cultural del género asociada al sexo. Algo que, al proporcionar -culturalmente- los medios para liberarse de un rol sexual no deseado, debe entenderse como un avance de la civilización; solo las posiciones más reaccionarias podrían ignorarlo. Pero eso afecta únicamente al género, el cual, como construcción cultural emancipadora- levantada sobre el sexo, sí es manipulable por el lenguaje. Por el contrario, el sexo mismo está fuera de nuestro alcance, no es construible ni deconstruible: dos lesbianas siguen siendo mujeres, aunque su conducta sexual y afectiva no encaje en el estándar social. Una

13 En efecto, entre las tribus primitivas, la homosexualidad -esto es, la asunción de un género diferente del atribuido al propio sexo- no es tolerable porque disminuye las posibilidades de mantener la tribu, que devendría inviable en el límite. Algo de lo que nuestras sociedades han podido, afortunadamente, prescindir. 
persona transexual puede ser declarada mujer u hombre mediante una ficción jurídica útil, pero seguirá siendo esencialmente un hombre o una mujer con tendencias atípicas en su sexo. Incluso si redujésemos la sexualidad a la genitalidad -lo que no es, desde luego, el propósito del proyecto feminista radical-, la alteración quirúrgica de, por ejemplo, unos órganos sexuales externos masculinos para darles la apariencia y funcionalidad de los femeninos dejaría intacto otro órgano masculino como la próstata y, huelga decirlo, no podría alterar la configuración cromosómica del sujeto. De hecho, esas eventuales manipulaciones (absurda la primera, imposible la segunda) no serían necesarias para liberar -emancipadoramente; no creo que se pueda, ni deba, negar esto- al sujeto de su disforia. Que, no en vano, la OMS denomina disforia de género ${ }^{14}$.

El texto que Butler dedicó al tratamiento de la intersexualidad por Foucault en El género en disputa (Butler 2007, 82) incide en algo que no hace sino avalar este argumento: la historia nos ha proporcionado, en efecto, cuerpos sometidos a la exigencia cultural de adscripción a un género, dado que se encuentran a mitad de camino entre un sexo y otro $^{15}$. Existe un hermafroditismo producido por la naturaleza y considerado tradicionalmente como teratológico por la cultura dominante, y su reconocimiento en términos dignos es fundamental para evitar el sufrimiento de quienes se reconocen identitariamente en él. Pero la materialidad -al menos, entendida en sentido propio- no puede ser, en este caso como en los no problemáticos, sino la que determina la configuración sexual; y esta viene dada (Connellana et al. 2000, 116; Lom-

14 La OMS afirma al respecto: "El género se refiere a los conceptos sociales de las funciones, comportamientos, actividades y atributos que cada sociedad considera apropiados para los hombres y las mujeres. Las diferentes funciones y comportamientos pueden generar desigualdades de género, es decir, diferencias entre los hombres y las mujeres que favorecen sistemáticamente a uno de los dos grupos" (consultado en https://www.who.int/topics/gender/es/).

15 Referido, como es sabido, al caso de H. Barbin: "Herculine no es una «identidad», sino la imposibilidad sexual de una identidad". Al respecto, el texto de A. González: "La subversión de la que habla Butler es performativa, es la de las acciones. En particular, las acciones del cuerpo subversivo son las que conducen a la problematización del Género, al Gender Trouble" (González 2009, 238). 
bardo et al. 2012, 680; Mc Carthy et al. 2012, 2247; Ingalhalikar et al. 2014; Sacher et al. 2013; Ngun 2011; Buss 1995) ${ }^{16}$, marca una serie de tendencias innatas derivadas del dimorfismo y no puede ser objeto de manipulación cultural. La construcción llega después, y lo hace hasta allí donde puede llegar: para sacar de lo teratológico a los individuos que presentan formas mixtas, asegurarles la libertad sexual sin cortapisas y una identidad en la que puedan vivir sin negarse, lo que supone una de las grandes contribuciones civilizatorias de la cultura del reconocimiento. Pero todo esto no afecta en modo alguno a la que considero objeción fundamental contra la teoría queer (no contra lo queer, que debería suscitar comprensión o, como mínimo, tolerancia en cualquier sociedad civilizada): el sexo no es disponible, el género sí. La configuración sexual no es resultado de una atribución cultural, el dimorfismo sexual y psicológico es funcional al mantenimiento de la especie y, por tanto, natural, y las desviaciones de la media son formas anómalas -no necesariamente patologías- que no hacen sino confirmar dicha media ${ }^{17}$.

Pero, más allá -o más acá- de esa indisponibilidad del sexo (que, ciertamente, solo aceptaremos quienes pensamos que existe lo real como algo previo a lo nombrable), relevante pero que no es lo esencial en

16 En particular, J. Connellana et al. establecen pautas claramente diferenciadas por razón de sexo en niños recién nacidos, que corresponde a una de las diferenciaciones más tópicas, la percepción abstracta o concreta de una figura: "In summary, we have demonstrated that at 1 day old, human neonates demonstrate sexual dimorphism in both social and mechanical perception" (p. 116). Igualmente M. V. Lombardo et al.: “...this study provides the first evidence that FT has an organizing effect on some sexually dimorphic areas of the human brain" (p. 680). Asimismo, M. M. Mc Carthy et al.: "There is compelling evidence of pervasive and robust differences between males and females in both normal and pathological conditions".

17 La distinción sustancia-accidente me parece aquí muy procedente, pese a su extracción metafísica. No veo por qué, si la falta de los dos brazos no es constitutiva de una "identidad manca", ya que consideramos sustancial a la figura humana la posesión de ambos y accidental su ausencia, no es posible sostener lo mismo con respecto al dimorfismo sexual, tanto físico como psicológico, tan estructural como la figura (porque ambos son forma). Lo accidental es solo lo no esencial y, por tanto, únicamente es anómalo si utilizamos el criterio de la especie, nunca cuando lo consideramos desde el de la personalidad y la ciudadanía; por tanto, inferir de dicha sustancialidad, como se hacía hasta hace bien poco, cualquier tipo de consideración denigratoria en el ámbito cívico (patológica, teratológica, inmoral...), para negar el reconocimiento y la vida digna, es un paso ulterior, que solo afrontaría una sociedad incapaz de integrar las diferencias y ella misma, en tanto que tal, patológica. El célebre autobús de Hazte Oír, el empeño de esta asociación cristiana integrista en negar que las formas intermedias son también configuraciones sexuales que reclaman reconocimiento y dignidad, no compasión o perdón, es un buen ejemplo de la facilidad con que el ultraconservadurismo identifica lo diferente con lo odiado. 
este texto, lo importante es examinar en detalle lo que hay tras esa aparente capacidad del postestructuralismo de Butler para deconstruir todas las cosas, todos los conceptos, todas las instituciones. Pues esa deconstrucción es la que hace imposible una justicia social no construida sobre el mapa, en cada momento concreto, de las vindicaciones identitarias más o menos coherentemente superpuestas, agrupadas o articuladas, ya que no existe un criterio que permita ordenarlas ${ }^{18}$.

Ante esa renuncia deliberada de lo queer a partir de núcleo normativo previo alguno, el problema del reconocimiento no debe, creo (y en ese aspecto Fraser está en lo cierto), afrontarse cuestionando su fundamento, que está plenamente justificado en un modelo social que se dice integrador de lo diverso y que solo los fundamentalistas cuestionarían; sino en la pretensión de constituir sobre ello toda vindicación, toda ética, toda política. Si la diversidad es una construcción (y lo es tanto como la pretensión de negarla), entonces puede ser cortada por los más diversos patrones, ampliable y recombinable hasta el infinito. Pues, recordémoslo, al no existir criterio alguno de ordenación, el todo resultante, de existir, no sería sino la mera suma de sus partes ${ }^{19}$, al

18 Butler, en aras de su negación de la dualidad privado-público, supedita la cuestión ética y la política al problema identitario: “... la cuestión de qué es lo que hace una vida vivible es anterior a la cuestión de qué tipo de vida podría yo vivir, y esto significa que lo que algunos llaman condiciones biopolíticas de la vida son en realidad las condiciones normativas que imponemos a la vida" (Butler 2017, 50).

19 En su pretensión de negar el carácter natural del dimorfismo sexual en el nivel cromosomático, Butler afirma, a partir de un experimento sobre divergencia entre dotación cromosomática y genitales externos: "Es evidente que estos son ejemplos en los que la suma de las partes componentes del sexo no redunda en la coherencia o unidad reconocible que suele nombrarse mediante la categoría de sexo" (Butler 2007, 219). Nuevamente la suma de las partes como criterio del todo: cuando el sentido se sitúa solo en dicha suma en cada caso concreto, resulta imposible mantener las anomalías bajo la figura del dimorfismo sexual, mientras que cuando el sentido se ve en el hecho de que la función (reproductora) genera la forma (dual), lo entenderemos como trascendental a todas las configuraciones, tanto las funcionales a la reproducción como las que no lo son. Las primeras tienen la condición de sustanciales, las segundas de accidentales; solo el hecho de hacer pasar a primer plano estas últimas, como hace Butler, altera la percepción del problema. Las anomalías cromosomáticas o genitales de sujetos determinados, las formas intermedias, no cuestionan el dimorfismo, como los mudos de nacimiento no nos hacen dudar de si el habla es esencial al género humano. Tampoco esta distinción entre lo esencial y lo accidental comporta, per se, discriminación alguna ni impide el reconocimiento: un individuo incapaz de reproducirse, sea cual sea su situación con respecto a la sexualidad mainstream, es un fracasado considerado desde un criterio filogenético, pero afortunadamente no lo es desde un punto de vista cultural, porque los seres humanos no actuamos como los babuinos. Motivo de más para mantener esa dualidad naturaleza- 
igual que en la perspectiva liberal. Nada trasciende la diversidad... más allá del deseo de trascenderla.

En efecto, el neolenguaje inclusivo procede por acumulación, nada hay en él de transversal: embarca categorías, pero desiste (ideológicamente, por convicción) a comprenderlas desde un orden. La propia denominación del conjunto de vindicaciones lo muestra: LGTBIQ+, donde no debemos olvidar que la $\mathrm{T}$ encierra a su vez tres posibilidades, de modo que eventualmente podría expresarse como LGTTTBIQ+. El signo final denota lo evidente: la especificación no tiene fin, puesto que disuelve lo estructural en lo funcional, lo físico en lo psicológico, lo dado en lo electivo, lo actual en lo potencial; y, de hecho, lo mezcla hasta tal punto que estas cuatro oposiciones serían cuestionables en términos estrictamente queer, en aras de un argumento tan analítico -y formalista- como su estructura binaria. El terror tradicional de las sociedades disciplinarias a la falta de elección de una opción sexual tiene su correlato simétrico en el rechazo de los teóricos de lo queer a cuanto impida, de un modo u otro, el tránsito de una de estas identidades a otra. La movilidad ha de ser total y no estar mediada, además, por reconocimiento institucional alguno, lo cual acaba generando problemas insospechados ${ }^{20}$. Esa sobrecarga del lenguaje se traduce con frecuencia en una sobrecarga correlativa de derechos y de leyes reguladoras, probablemente innecesarias en su mayoría si se recondujese la cuestión de la identidad sexual a una interpretación amplia de los bienes y derechos de la personalidad y de los derechos civiles, en conjunción con las normas penales que defienden la identidad asumida, cuyo correlato debería ser el carácter privado de la opción de género en cuanto reveladora de la libertad sexual. Pero la teoría post ha hecho imposible mantener este esquema, ya que su vinculación de las formas de subjetivización con lo político presupone, precisamente, la indistinción entre el ámbito

cultura tan cuestionada por las teorías queer: negarla es absolutizar el término que elegimos como único referente.

20 Como el de la irrupción de las atletas trans hombre-mujer en el deporte femenino, en perjuicio de las deportistas, o el de la reversión de las operaciones de cambio de género. 
de lo público y de lo privado: pues para ese discurso que constituye subjetividades performativamente y niega toda estructura binaria, todo es, a la vez, subjetivo y político y, además, es lo segundo por y en tanto que es lo primero.

Por ello, la multiplicidad de derechos subjetivos fragmentados y leyes ad hoc es habitual en un panorama orientado hacia lo queer, fundamentalmente debido a que este tipo de legislación no comporta tan elevadas cargas presupuestarias como las leyes que fijan derechos relativos a la dependencia, las pensiones, el salario mínimo... Por otra parte, esas leyes exhiben una concepción fragmentada típica del discurso queer, ya que abordan problemas en sí universales como la agresión, la prepotencia, el desprecio del otro, desde la óptica de la diferencia y la particularidad (por ejemplo, el género), al entender que deben incluir un plus de reprensión social vinculado, no a la pura y simple reprochabilidad del hecho en sí, sino a las circunstancias en que se produce; pues tanto el sujeto activo como el pasivo son redefinidos como parte de un grupo. Es en este punto donde la ideología post quiebra más claramente la tensión equilibrada entre lo universal y lo particular propia del principio de justicia tradicional (y, me temo, en gran medida la presunción de inocencia), ya que implícitamente se acepta que unas agresiones son diferentes de otras, pero la diferencia entre ellas no está en la consideración del caso concreto, sino que viene introducida legalmente iuris et de iure ${ }^{21}$.

\footnotetext{
21 Es muy reveladora al respecto la STS 677/2018, de 20 de diciembre de 2018, dictada en un caso de agresión recíproca, que presume la violencia de género en cualquier tipo de violencia ejercida por un hombre contra una mujer en el ámbito de una relación previa. En la sentencia se afirma que "...los actos de violencia que ejerce el hombre sobre la mujer con ocasión de una relación afectiva de pareja constituyen actos de poder y superioridad frente a ella con independencia de cuál sea la motivación o la intencionalidad". El voto particular sostenía: "Partir de la base de que concurre el elemento que justifica el trato desigual es contrario a la presunción de inocencia. $Y$ hacer que el acusado responda, de modo automático y mecánico, de una característica de la conducta, necesaria para justificar la desigualdad de trato, que no se ha probado en el caso, además, vulnera el principio de culpabilidad".
} 
5. LOS PROBLEMAS TEÓRICOS DE LO QUEER: EL USO Y ABUSO DE LOS PERFORMATIVOS Y LA CONSTITUCIÓN LINGÜÍSTICA DE LA IDENTIDAD.

La crítica de esa negativa del feminismo de tercera generación a conseguir una teoría que vaya más allá del identitarismo no puede ser acometida sin:

-Una crítica del uso de los performativos, su principal herramienta teórica.

-Una crítica correlativa de la evolución del concepto de identidad, que es el resultado de la subjetividad moderna.

Butler ha reiterado y afianzado en Cuerpos que importan su convicción de que el género, y el sexo mismo, son productos normativos, generados mediante prácticas de poder repetidas performativamente, que acaban por crear la materialidad a la que se refieren (Butler 202, 12) ${ }^{22}$. Su concepción de los performativos no es, obviamente, la de Austin: no lo entiende ya como una voluntad humana que se proyecta en el lenguaje, sino “...una modalidad específica del poder, entendido como discurso". En ese mismo texto, vincula inescindiblemente sexo y poder mediante el discurso: al afirmar que la diferencia sexual está marcada por prácticas discursivas de demarcación -aún más, que es indisociable de estas-, considera que "...el "sexo" no sólo funciona como norma, sino que además es parte de una práctica reguladora que produce los cuerpos que gobierna...” (Butler 2002, 267, 17 y 18). Butler se preocupa de afirmar que no considera que el discurso cause la diferencia sexual. No cabe sino agradecérselo.

Nuevamente un lenguaje privado de todo referente ontológico (e incluso de sus sustitutos consensualistas) rebasa el ámbito de lo acep-

22 La autora estadounidense sostiene en este texto que lo sexual se construye a través de las relaciones de poder, mediante "...restricciones normativas que no sólo producen sino que además regulan los diversos seres corporales (...) la materialidad del sexo se construye a través de la repetición ritualizada de normas". 
table: ni el sexo se reduce a un discurso, ni dicho discurso es capaz de producir cuerpos. A lo más, de generar e interpretar sus prácticas. La combinación de la performatividad con el identitarismo fragmentado sobre el que recae nos conduce inevitablemente, creo, a una reificación de la identidad, precisamente como consecuencia de su desestructuración: pues las identidades definidas normativamente desde el discurso hegemónico en términos dualistas pueden ser profundizadas, en clave contrahegemónica, casi hasta el infinito. Y pueden serlo en aras de un designio individual carente de todo referente objetivo (institucional) necesario, lo que hace que la identidad en clave contrahegemónica que vindica la teoría queer sea, tanto como su precedente, el resultado de una imputación, una -por ser más preciso- autoatribución que no hace sino seguir el designio de una identidad autopercibida y, en tanto que autoimputada, creada, en pugna con la heteroatribución y heteropercepción que caracterizan a la creación correlativa de la identidad normalizada por el poder.

La identidad postmoderna es, pues, siempre una elección, y una elección dada en el ámbito de la "materialidad discursiva", porque no conoce ya referente biológico ni institucional alguno. Es electiva cuando el poder la impone; lo es cuando el sometido vindica una identidad diferente. No juzgo en sentido alguno tal hecho, me limito a señalarlo como tal. Esto -la elección contrahegemónica por parte del sujeto de su género y de la sexualidad (no del sexo) en el cual se reconoce- puede asumirse o no, pero creo que su aceptación es algo perfectamente normal para cualquier persona de ideología no conservadora, siempre que esa teoría sobre la identidad electiva se mantenga dentro del ámbito de lo disponible, el del género. Cuestión diferente, que no puedo tratar ahora porque llevaría muy lejos, es la ausencia de institucionalidad en la atribución, que está llamada a generar multitud de problemas ${ }^{23}$. El

23 Pensemos en la creciente tendencia de algunos varones en el curso de procedimientos judiciales a atribuirse la condición autopercibida de mujer, lo que resulta teóricamente posible al no existir intervención institucional alguna al respecto. Se trata, sin duda, de un fraude de ley, pero no deberíamos perder de vista que una concepción queer instalada en el sistema jurídico lo permite y 
principal escollo, a mi entender, es que -digámoslo con la radicalidad que requiere-estas vicisitudes de las identidades individuales autopercibidas pueden llegar a convertirse en el tema fundamental de una (anti)filosofía política basada en el reconocimiento de la identidad como diferencia, y no en la búsqueda de la igualdad. Veamos, sin embargo, lo que sostiene Butler al respecto:

"En este sentido, lo que constituye el carácter fijo del cuerpo, sus contornos, sus movimientos, será plenamente material, pero la materialidad deberá reconcebirse como el efecto del poder, como el efecto más productivo del poder. Y no habrá modo de interpretar el 'género' como una construcción cultural que se impone sobre la superficie de la materia, entendida o bien como el 'cuerpo' o bien como su sexo dado. Antes bien, una vez que se entiende el 'sexo' mismo en su normatividad, la materialidad del cuerpo ya no puede concebirse independientemente de la materialidad de esa norma reguladora. El 'sexo' no es pues sencillamente algo que uno tiene o una descripción estática de lo que uno es: será una de las normas mediante las cuales ese 'uno' puede llegar a ser viable, esa norma que califica un cuerpo para toda la vida dentro de la esfera de la inteligibilidad cultural" (Butler 2012, 19).

$\mathrm{Y}$, sin embargo, la materialidad es previa al poder; la distinción sexual se da, por su condición tercamente material, en el más primario de los sentidos 24; el sexo es, contra lo que afirma Butler, "algo que uno tiene”. El sexo no surge, en sí mismo, como algo teñido normativamente, salvo que nos obstinemos en afirmar que cualquier cosa puede ser

que no poseemos, en principio, medio alguno para evitar esa práctica, precisamente por la ausencia de control institucional sobre la autoatribución. Así lo expresa la Ley 2/2016, de 29 de marzo, de Identidad y Expresión de Género e Igualdad Social y no Discriminación de la Comunidad de Madrid, que en su art. 4 afirma: "Toda persona tiene derecho a construir para sí una autodefinición con respecto a su cuerpo, sexo, género y su orientación sexual. La orientación, sexualidad e identidad de género que cada persona defina para sí es esencial para su personalidad y constituye uno de los aspectos fundamentales de su dignidad y libertad (...) En el ámbito de aplicación de esta Ley, en ningún caso será requisito acreditar la identidad de género manifestada mediante informe psicológico o médico" (la cursiva es mía).

24 Un buen ejemplo de que lo material no es necesariamente lo económico. Si Butler ha abandonado de hecho en su teorización cualquier forma de socialismo, es precisamente porque ha prescindido de la primacía - no necesariamente exclusividad- de la escala de lo económico y ya no la concibe sino desde la de la identidad. 
dicha en cualquier contexto. Es algo natural, pese a quien pese; lo cual no impide, insisto, su recalificación cultural, emancipadora o no, esto es, el género. Pero dicha recalificación de un cuerpo es normativa y por ello, en tanto que cultural, no natural. El cuerpo, en su diferenciación sexual, precedió a la lengua que es la vía para calificarlo normativamente en millones de años; fuimos humanos mucho antes de tener formas culturales. Cuando Butler sostiene que “...el 'yo' hablante, se forma en virtud de pasar por ese proceso de asumir un sexo”, está desviando dicha asunción desde su lugar propio, que es el del género, hasta el del sexo. No se asume un sexo, sino un rol sexual; solo una reificación extrema del lenguaje, un destierro total de su función representativa como el que propone Laclau con sus significantes flotantes ${ }^{25}$, puede ignorarlo. La especie humana está configurada biológicamente, como todas las demás. Es la sociedad humana la que se configura normativamente a través de patrones impuestos: tener que aclarar esto resulta chocante.

Esta insólita atribución al lenguaje de poderes creadores (no genera los cuerpos, pero sí su materialidad, como si esta fuera tan disponible como los roles) no es extraña en la filosofía post, con su deconstrucción, ya referida, de los pares que vertebraron la modernidad y, entre ellos, la oposición naturaleza-cultura ${ }^{26}$. Creo que no carece de importancia recordar hasta qué punto se desvía la teoría performativa de Butler desde el ámbito en que fue inicialmente concebida por Austin puede resultar

25 De hecho, Butler toma como referente a Zizek, que hace suya una concepción similar a la de Laclau y la suya: "Los significantes políticos, especialmente aquellos que designan las posiciones de los sujetos, no son descriptivos, es decir, no representan sectores previamente dados, sino que son signos vacíos que llegan a cargarse de investiduras fantasmáticas de diversa índole. Ningún significante puede ser radicalmente representativo, pues todo significante es el sitio de una méconnaissance perpetua; produce la expectación de una unidad, de un reconocimiento pleno y final que nunca puede alcanzarse. Paradójicamente, la incapacidad de tales significantes -"mujeres" es el que se me ocurre en este momento- para describir acabadamente el sector que nombran es precisamente lo que los constituye como sitios de investidura fantasmática y rearticulación discursiva. Esa falla es lo que los abre a nuevas significaciones y nuevas posibilidades de resignificación política. Esta función performativa y de final abierto del significante me parece esencial para construir una noción democrática radical de las posibilidades futuras" (Butler 2012, 272).

26 "El análisis que presenta a la naturaleza como singular y prediscursiva no puede preguntar: ¿que puede considerarse «naturaleza» dentro de un contexto cultural dado, y con qué finalidad? ¿Es necesario para algo el dualismo? ¿Cómo se establecen los dualismos sexo/genero y naturaleza/cultura y cómo se normalizan uno a través del otro?” (Butler 2012, 105). 
ilustrativo. Este filósofo, como es sabido, entendía los enunciados performativos como aquellos que producen la realidad que describen, pero dicha realidad se entendía referida a su proyección institucional. Por ejemplo, la declaración de matrimonio pronunciada por un sacerdote, la sentencia de un juez, la orden impuesta por un superior jerárquico, no son realidad en sentido primario; pertenecen al tercer género de materialidad (Bueno) o al mundo tres (Popper), esto es, al ámbito de los productos culturales. Igualmente, los performativos de Butler no crean la realidad ni la sustituyen, salvo en el ámbito citado. Y esto confirma lo que sostuve anteriormente: la pretensión de que no solo el género, sino también el sexo es modificable mediante performativos (ya por el poder que impone formas y conductas, ya por la resistencia contra él) es incorrecta. El poder patriarcal puede, y de hecho pudo históricamente, imponer una sumisión de las mujeres en el ámbito familiar, pero esto tiene que ver con el rol cultural del sexo femenino, no con el sexo femenino mismo, que se halla en el modo de materialidad más basal (primer género de materialidad en la distinción de Bueno; Mundo Uno en la de Popper).

Aunque el poder hubiese impuesto otras formas totalmente diferentes, estas habrían afectado a la interpretación cultural del sexo femenino, no al sexo mismo. Varones y mujeres habrían continuado reproduciéndose del mismo modo y con las mismas consecuencias (y, por supuesto, con las mismas anomalías; las mismas disidencias abiertas o solapadas; las mismas identidades, ya hegemónicas, ya derrotadas, reprimidas o toleradas) aunque la forma cultural occidental hubiese sido el matriarcado. El discurso sobre la sexualidad ha creado, ciertamente, las identidades de género, pero no las sexuales, que, reitero, no son disponibles. Negar esto no es sino un escalón más en la eterna lucha de los post contra lo real; una lucha ya antigua que pasa por Althusser, Lacan, Foucault, Zizek y la propia Butler. En la filosofía de esta autora, como en el pensamiento post en general, la absolutización de la identidad no es comprensible sin entender previamente la disolución de 
todo contenido real en el lenguaje, hasta el punto de que este determina la materialidad, es materialidad ${ }^{27}$ :

"Postular una materialidad que esté fuera del lenguaje continúa siendo un modo de postular esa materialidad, y la materialidad así postulada conservará esa postulación como su condición constitutiva. Postular una materialidad exterior al lenguaje, considerada ontológicamente distinta del lenguaje, equivale a socavar la posibilidad de que el lenguaje pueda indicar o corresponder a ese ámbito de alteridad radical. Por ello, la distinción absoluta entre lenguaje y materialidad que procuraba asegurar la función referencial del lenguaje socava radicalmente esa misma función" (Butler 2002, 109).

Quizá sea en esta insólitamente redundante frase donde Butler muestra con más claridad su nominalismo extremo: nos dice, literalmente, que no hay materialidad fuera del lenguaje o, por ser más precisos, que no hay modo de constatarla ${ }^{28}$. Como la propia autora ha afirmado a propósito de Zizek, lo real no puede ser significado, sino que permanece “...como la resistencia que está en el corazón mismo de toda significación” (Butler 2002, 292). Analicemos la frase anterior de Butler. Para Jakobson, como es sabido, las funciones del lenguaje son referencial, emotiva, apelativa, fáctica, metalingüística y poética; solo la primera, que Butler niega, permite establecer un valor de verdad -ya consista este en una correspondencia o en una adecuación- y dar cauce a una cierta pretensión de objetividad; esto deja a su teoría performativa en mala posición con respecto a lo real. Ciertamente nada nuevo, pues la

27 Una visión que Butler toma de Althusser: "Diremos entonces, tomando en consideración un sujeto (tal individuo), que la existencia de las ideas de su creencia es material en cuanto sus ideas son actos materiales insertos en prácticas materiales normadas por rituales materiales definidos por el aparato ideológico material del cual derivan las ideas de este sujeto" (Althusser 2005, 138) Por supuesto, Althusser se ve obligado a admitir que desplazamientos, frases, oraciones, miradas o discursos de la conciencia no son iguales, lo que obliga a plantearse -y a dejar en suspenso- los modos de la materialidad.

28 "Esto no significa que, por un lado, el cuerpo sea sencillamente materia lingüística (...) no es que uno no pueda salirse del lenguaje para poder captar la materialidad en sí misma y de sí mismo; antes bien, todo esfuerzo por referirse a la materialidad se realiza a través de un proceso significante que, en su condición sensible, es siempre-ya material (...) lo que permitirá que un significante signifique nunca será solamente su materialidad; esa materialidad será a la vez una instrumentalidad y un despliegue de una serie de relaciones lingüísticas más amplias" (Butler 2002, 110). 
cuestión ya se planteaba en el Foucault de El orden del discurso, hace medio siglo.

Butler, en cualquier caso, hace trampas con los adverbios. Es difícil encontrar a alguien que distinga absolutamente lenguaje y materialidad más allá del ámbito temporal al que limita sus estudios, los siglos XX y XXI: el tiempo de Heidegger, la filosofía analítica, la hermenéutica filosófica y el lingüistic Turn. Los adverbios pueden ser peligrosos: como las matemáticas, no mienten, pero sirven para mentir. La materialidad es extralingüística; aceptar que nuestro pensamiento es lingüístico no significa reducir a lenguaje cuanto con él aprehendemos, incluida la realidad. La crítica post del cartesianismo y de su pretensión de distinguir y separar plenamente palabras y cosas mediante estructuras matemáticas y geométricas, el rechazo de la representación univocista que pretende, no ha de conducirnos al extremo opuesto, la disolución de lo real en el lenguaje. Y eso es lo que afirma Butler: que el lenguaje, cuando se entiende como práctica de poder (y sin duda lo es, pero es mucho más), aparece como constitutivo de la materialidad misma, y la constituye del modo más radical: sin que pueda afirmarse cualquier tipo de gramática del nosotros o del yo. La autora sugiere un vocabulario “...que resista la sustancia metafísica de las formaciones sujeto-verbo y, en su lugar, se apoye en una ontología de los gerundios” (Butler 1998, 299).

Estimo que esta frase, genuinamente post, designa un auténtico dislate. Tampoco creo que desde la propia perspectiva de Butler se pueda hablar de algo así (sin asomo de licencia alguna, ya que no utiliza comillas). De entrada, el propósito de eliminar todo referente que no sea lingüístico -pues es lingüísticamente como se configuraría incluso la materialidad- no se compadece bien con el término ontología; en todo caso, se trataría de una epistemología de los gerundios. Esta es una de las mayores paradojas de Butler y los post: desustancializan o deconstruyen prácticamente todo el arsenal conceptual de la Modernidad y, a la vez, pretenden establecer una ontología, que pertenece a 
dicho bagaje, ignorando que no hay ontología posible en un mundo nominalista radical. Si ya el propio empeño de Foucault de conseguir una ontología del presente mediante su genealogía del saber era cuestionable, el de Butler lo es aún más. Si la “...sustancia metafísica de las formaciones sujeto-verbo" a que se refiere la autora (formaciones que, dicho sea de paso, no son metafísicas per se, porque pueden ser apropiables por cualquier tipo de pensamiento, siempre que pretenda hablar desde un mínimo sentido) ${ }^{29}$ ha de ser asimismo deconstruida, dado que el yo no es sino “...una forma de ir tomando cuerpo” y el qué es solo la corporeización de las posibilidades, no parece que reste mucho espacio para una ontología que, además, descansa en algo tan lingüístico tan gramatical- como el gerundio ${ }^{30}$. La identidad tal y como la concibe Butler no permite este tipo de conceptos, salvo de forma irónica; al no existir sino como una simple performance, es pura posibilidad. Y la posibilidad es, recordemos, la categoría fundamental de lo moderno ${ }^{31}$, aunque en los post se presenta sin el apoyo de principio ordenador alguno: si la significación cultural de los cuerpos es performativa, si la identidad de género no es más que una sucesión de actos, “...entonces no hay identidad pre-existente que pueda ser la vara de medición de un acto $\mathrm{o}$ atributo (...) y el postulado de una verdadera identidad de género se revela como una ficción regulativa" (Butler 1998, 310). Me temo que aquí no queda lugar alguno para hablar de una ontología, siquiera en el menos propio de los sentidos. En cuanto al sentido de especular sobre una utilización de la lengua que desconfíe de la estructura sujeto-verbo y se centre en los gerundios, desde luego es un empeño que puede conducirnos muy lejos, pero no sé si a lugares interesantes. No deberíamos

29 La célebre proposición 7 del Tractatus de Wittgenstein podría servir de ejemplo: De lo que no se puede hablar, hay que callar. Dada su estructura sujeto-verbo, ċdebemos considerarla metafísica?

30 La propia Butler afirma que la categoría universal que llamamos mujer “...entraña la falsa promesa ontológica de una probable solidaridad política” (Butler 1998, 303); sorprende que el mismo término pueda ser utilizado sin violencia para designar tanto este significado como el relativo a la inefable ontología del gerundio.

31 En esto se muestra la esencial continuidad entre lo moderno y lo postmoderno: ambos se asientan en lo posible fente a lo real, como vimos al comienzo de este texto. 
olvidar que Butler y los post tienen antecedentes en este singular empeño de traducir a la lógica del delirio toda estructura conceptual o científica: baste recordar la vieja afirmación de que las matemáticas son fascistas o la célebre necedad de Luce Irigaray sobre el carácter sexista de la ecuación de la teoría de la relatividad general (Sokal et al. 1999: 116). Esta utilización de la performatividad, que roza lo irracional, deriva de la singular alegría con que Butler, y los post en general, manejan la terminología filosófica:

"Responder a la pregunta de la relación entre la materialidad de los cuerpos y la del lenguaje exige primero que ofrezcamos una versión de cómo se materializan los cuerpos, es decir, de cómo llegan a asumir la morphe, la forma mediante la cual queda marcado su carácter distintivo material. La materialidad del cuerpo no debe darse por descontada, porque en cierto sentido se la adquiere, se la constituye, mediante el desarrollo de la morfología" (Butler 2002, 113).

Nuevamente la absoluta disponibilidad del lenguaje post nos pone en un aprieto: la forma no materializa, la forma informa... como su nombre indica. Lo cual, por cierto, no comporta ni la separación, ni la absolutización de los conceptos de materia y forma, ni su utilización idealista. Salvo que demos por bueno que cualquier término puede adoptar cualquier significado (y aparentemente es lo que se pretende que aceptemos), la frase de Butler es errónea y confundente. En un cuerpo humano, forma y materia se imbrican mutuamente: ninguna de ellas causa la otra. Carece de sentido decir que el otorgamiento de una forma materializa un cuerpo; en todo caso, ayudará a verlo de otro modo. Nuevamente la filosofía materialista de Althusser espesa y hace problemática y confusa la concepción de Butler. Aquí está, en cualquier caso, la clave última de la teoría de la estadounidense sobre la constitución cultural del sexo y la disponibilidad de lo biológico; y, como hemos visto, son el nominalismo, el performativismo y la concepción materialista de la identidad sus claves. 
En el nominalismo, no en vano resultado de una polémica teológica medieval sobre los posibles límites de la voluntad divina, no existe límite lógico (excepto el principio de no contradicción), lingüístico, natural ni ético para la voluntad ilimitada de Dios, pues entre las cuatro causas solo la causa eficiente tiene estabilidad, precisamente por su referencia necesaria al artífice: el significado de las palabras es el que decide Dios de potentia absoluta ${ }^{32}$. En Butler, representante cualificada del nominalismo radical contemporáneo, ocurre lo mismo, aunque aquí el papel de la deidad lo cumple el discurso, ya hegemónico, ya contrahegemónico. Esto debe quedar claro: no es solo el poder quien llena de contenido las cáscaras vacías de las palabras, también el resistente hace lo mismo en la medida en que tiene poder para ello. En uno y otro caso, la realidad es solo un principio que debe llenarse de sentido mediante una imputación de significado, siempre inestable, siempre transitorio33. De ahí que la categoría del género no pueda servir ya como punto de partida estable en el feminismo queer, pues se trata de un concepto universal34. Y surge la pregunta, tantas veces formulada, de si este cuestionamiento del género no condena a la teoría feminista a disolverse 35 .

32 No hay, por tanto, diferencia en preguntar si Dios pudo haber venido al mundo como una mosca, como hacían los nominalistas bajomedievales, o en cuestionarse si una ecuación es patriarcal. El mundo de lo cierto tiene límites, por más borrosos que resulten a veces, pero el de lo posible (en el sentido más amplio, el que no necesita a lo real) es ilimitado.

33 Así es como define la también nominalista Mouffe (a partir del concepto wittgensteiniano de juego del lenguaje) a los conceptos de clase social, raza, bien común, género... (Mouffe 1992, 15; 1999).

34 Una feminista de la igualdad como C. Amorós, tributaria de una epistemología moderadamente nominalista y de un activismo feminista, cuestiona muy lúcidamente la deriva queer: "¿Términos tales como 'hombre' o 'mujer' no significan nada? Si fuéramos nominalistas radicales tendríamos que decir que, en rigor, no (...) Pero difícilmente, en ese caso podríamos mantener posiciones feministas (...) Pues bien, ser nominalista moderada o no radical significa hacerse cargo de este peculiar tipo de entidad que los genéricos connotan negándose al mismo tiempo a esencializarla". Algo que, como bien advierte Amorós, debería estar entre una esencia y un mero nombre; posición que, como es sabido, corresponde al nominalismo ockhamiano, que establece una realidad universal de los conceptos (Amorós 1992, 42).

35 Mouffe, que parte de la inestabilidad "esencial" (no deja de resultar chocante que lo único esencial sea precisamente lo que se opone a la esencia) de las posiciones de sujeto, niega que esto condene a la desaparición al discurso feminista, pero llega a una conclusión similar: "Mi tesis es que, en el dominio de lo político y por lo que toca a la ciudadanía, la diferencia sexual no debe ser una distinción pertinente" (Mouffe 1996, p. 11). 
Pero no todo se esfuma en una teoría post: de hecho, y solo en apariencia paradójicamente, la identidad crece hasta invadirlo todo. El llamado antiesencialismo (que tritura todo significado estable para ponerlo a disposición del poder que impone o del contrapoder que resiste) produce una auténtica reificación de lo identitario; no porque haya esencia alguna en la identidad, que no la hay, sino porque no existe ya problema más radical que el identitario, que se halla en el punto donde las prácticas hegemónicas o contrahegemónicas configuran -siempre inestable, siempre precariamente- al sujeto. Esta reificación de la identidad se produce, por cierto, en un sentido radicalmente opuesto al que manejan los comunitaristas (los otros grandes identitaristas contemporáneos), pero la omnipotencia de la identidad, constituida como diferencia, es igual: simplemente, en un caso se construye a la escala individual y en el otro a la colectiva. La identidad, concebida con la factura lingüística que los post le otorgan, puede mutar de continuo al albur de maniobras lingüísticas. No hay identidad estable alguna, precisamente porque ya todo es identidad. No es casual que ello comporte la desaparición progresiva de la institucionalidad, que en la filosofía post queda asociada a mera presencia del discurso hegemónico.

En suma, la filosofía queer

-arranca de una matriz feminista que, al negar todo concepto estable capaz de designar una realidad, hace imposible buena parte de su propio discurso;

-es tributaria de un postmarxismo que, al negar la autonomía del discurso emancipador, lo disuelve en las pretensiones de reconocimiento de cada sujeto.

Intentaré mostrar que esta doble aporía ilustra muy bien sobre la crítica post a la Modernidad, que realmente no hace sino exacerbar el carácter absolutizador de esta. Igualmente, sostendré que una comprensión hermenéutica y analógica permite obviar las aporías de lo queer. 


\section{UNA SALIDA HERMENÉUTICA DE LAS APORÍAS DE LO QUEER}

La identidad entendida como diferencia es, en fin, el núcleo normativo de la filosofía queer ${ }^{6}$. Desde la comprensión hermenéutica analógica que aquí se sostiene, por el contrario, ni la diferencia es la clave de la identidad (discurso equivocista), ni al contrario (discurso univocista); tampoco hay una dialéctica entre unidad y diferencia, sino una analogía en la cual cada una de ellas se entiende en función de la otra, en una comprensión recíproca que permite comprender lo político sin reducirlo a las políticas ni circunscribirlo a lo identitario (Gómez, 2017; 2018, 63 y ss.). Una identidad anterior a toda diferencia es una abstracción típicamente liberal; por el contrario, una diferencia constitutiva es una concreción característicamente postmoderna. Con todo, los post son similares a los liberales en muchos aspectos: el mundo escindido, individualista, discreto que construyen (que es un punto de llegada para los segundos y de partida para los primeros) diluye todo intento de invocar un bien común: en el primer caso por la negación de los universales éticos que desarma todo discurso de la resistencia organizada, en el segundo a causa del culto a la iniciativa individual organizada en el mercado.

La neorreligión de la diferencia ha tenido sobre la filosofía política actual de izquierdas el efecto de un tumor maligno, disolviéndola en especulaciones progresivamente autorreferentes, envueltas en un lenguaje cada vez más truculento y que en ocasiones roza la jerga grotesca. El reparto de los bienes en el mundo es cada vez más injusto (no simplemente desigual: la justicia es la igualdad atravesada por un criterio); el capitalismo en su forma mundializadora y financiera esparce por doquier miseria, esclavitud legal, neocolonialismo, expulsión de poblaciones, estados de excepción y destrucción de la naturaleza; las instituciones neoliberales (BM, FMI, OMC, UE) defienden los recortes socia-

36 “...la diferencia es la condición de posibilidad de la identidad o, mejor, su límite constitutivo: lo que hace posible su articulación y, al mismo tiempo, lo que hace posible cualquier articulación final o cerrada" (Butler 2016, 74). 
les como una exigencia de toda buena gobernanza; se extiende por doquier la certeza de que gobernar es gestionar; la extrema derecha neoliberal se hace con el control de estados como EEUU o Brasil y la socialdemocracia cumple más que nunca con su función sostenedora del sistema (precisamente, y en gran medida, mediante un entusiasta e interesado apoyo a las guerras culturales, lo único que la separa de la derecha). Mientras tanto, una parte muy relevante de los intelectuales de la sedicente izquierda cuestiona el concepto de lucha de clases, y aun el mismo concepto de clase social, jugando interminablemente a deconstruir las bases teóricas que en su día articularon con eficacia la pretensión de igualdad, ya la de todos los hombres, ya de los varones y las mujeres (no deja de resultar paradójico que hoy, tras tantas conquistas en pos de la igualdad, en muchos medios académicos feministas el término mujer genere suspicacia). Aunque formalmente lo queer no renuncia a la igualdad, en el diseño efectivo de sus estrategias lo único importante es lo que nos diferencia. El ya citado M. Lilla en el ámbito estadounidense y D. Bernabé entre nosotros -el primero desde la moderadísima perspectiva de los liberales estadounidenses, el segundo desde un marxismo no postmoderno-, han denunciado los letales efectos sobre la izquierda política de sustentar la lucha contra la injusticia en las identidades, la enervación profunda de las pretensiones emancipadoras que esto comporta. Algo, a mi entender, muy grave en quienes se dicen postmarxistas.

En este panorama de desactivación de la justicia social, la filosofía (anti)política queer cumple el papel de justificadora del sistema capitalista, al que no daña ni atemoriza: su efecto sobre aquel es inexistente y su capacidad movilizadora nunca toca lo esencial, la justicia distributiva. Las luchas culturales, separadas de su matriz redistributiva, son como una naumaquia librada en una piscina: un artificio mínimo que cumple la función de entretener, en los dos sentidos del término.

Trascender las diferencias -propósito típico de una hermenéutica de cuño analógico- no significa olvidarlas ni domesticarlas o subordi- 
narlas, sino defenderlas en el lugar que les es propio: en este caso, dejando la identidad en el ámbito de lo privado, evitando que todo se haga público, lo que es propio de una sociedad totalitaria, y permitiendo que lo público entre en este ámbito solo en caso de que la agresión contra dicha identidad haya de tener relevancia penal. Desde una comprensión hermenéutica, ha de entenderse lo particular desde lo común, no al revés; y lo común existe, no como una unidad unívoca, reductora a notas idealistamente definidas, sino análogamente. Lo político, hoy, no puede ser una suma de vindicaciones a las que nada cruza y une salvo el hecho de ser tales, sino el sentido mismo de ausencia que hay tras ellas: la ausencia de la justicia, del bien común. Las dualidades que esta concepción reintroduce, por cierto, no comportan dualismos, salvo para quien las esgrime paródicamente: solo hay dualismos cuando la contraposición se absolutiza... o cuando, no menos artificialmente, se pretende ignorarla. El problema de Butler, que pretende huir de las absolutizaciones de la Modernidad, sus dualismos y el idealismo que esconden, es, paradójicamente, su propio lenguaje relativista que, en tanto que tal, está absolutizado. En él no cabe la analogía, porque no cabe la relación (ni, por tanto, la comunidad); se ha pasado de un solo modo de definir a la inexistencia de regla alguna para hacerlo, más aún, a la negación de toda necesidad de definir. La filosofía queer padece la limitación propia de cualquier nominalismo radical, que reduce el todo a sus partes y lo social a un conjunto precario de individuos, mantenido como totalidad gracias a constructos lingüísticos instrumentales. Esto no es novedoso en la fase final de la Modernidad, pues la absolutización, lejos de ser una práctica metafísica, cruza todo el panorama filosófico y se puede producir en modos muy diferentes: fundamentalmente, la del Estado (totalitarismos), el sistema (funcionalismos extremos) o el individuo (liberalismo, postestructuralismo). Y, en una solo aparente paradoja, cuanto más escéptico se dice ser, más se absolutiza. En un discurso nominalista toda individualidad, toda discreción, son absolutas, porque suponen la realidad última y única; esto implica la negación de toda 
relación, de toda sustancia (y, por tanto, de todo accidente); algo inevitable, pues una y otra son categorías y el nominalismo las niega.

No debe juzgarse a nadie por sus compañeros de viaje, pero los de Butler son, lo acepte o no, muy cuestionables. El grado de disolución de lo común en lo individual no es muy diferente en el anarcoliberalismo de Nozick, preconizador del Estado mínimo, y en el constructivismo postestructuralista de Butler, aunque sus ideologías sean muy diferentes. La vida humana, tanto la privada como la íntima, es ante todo relación; si lo aceptamos, aceptaremos también que el orden de lo político se da en la comunidad (que es, como su nombre se indica, común, y que no excluye los enfrentamientos) y ese orden es, además de algo dado, anterior ontológica y cronológicamente al del sujeto (que es, en esto no yerra Butler, un constructo moderno). Lo que no significa aceptar dicho orden acríticamente, sino saber de qué se parte antes de superarlo, como sostuvo Gadamer. Toda concepción de lo social y político centrada en el individuo como mero factor de suma es una abstracción del mundo, que no hace sino exacerbar el modelo hobbesiano de reducción del todo a sus partes. No en vano uno y otro son nominalistas 37.

37 "Judith Butler reconsidera críticamente las estrategias que admiten al cuerpo cristalizado en estructuras sociales/lingüísticas fijas y el supuesto según el cual 'no hay más allá del lenguaje'. A nuestro juicio, este es el caso de un hiperconstructivismo del que la autora intenta distinguirse. De cara a esta posición de tipo nominalismo radical -que determina completamente la actividad de los sujetos y que excluye la posibilidad de trasformar el estado de cosas mediante los actos singulares y colectivos- Butler se inclina por el concepto de performatividad entendido en términos de reiteración. A su vez, ello la habilita a pensar un "haciendo", antes que un "hacer" que demanda un sujeto de la acción. En efecto, el nuevo constructivismo que defiende Butler puede sintetizarse mediante su propio interrogante: “¿Cómo puede haber una actividad, un acto de construcción, sin presuponer la existencia de un agente que preceda y realice tal actividad?” (Butler, 2002: 25). Niega de este modo que el agente cabal de la construcción sea algo (como el lenguaje) o alguien (como la persona), rechazando así tanto las estructuras fijas como la apelación a algún estrato metafísico del sujeto individual que origine la construcción" (De Santo 2015, 35-36). Al parecer, cierta teoría post ha deconstruido el nominalismo que utiliza para deconstruir; doctrina que, si algo implica, es precisamente el llamado antiesencialismo de Butler, su reducción de las frases con estructura sujeto-verbo a enunciados metafísicos. Resulta irrelevante que pensemos en un haciendo o en un hacer; lo importante es qué se hace y quién lo hace. Y el nominalismo crea lo real a partir del lenguaje; en ningún caso "determina completamente la actividad de los sujetos" ni "excluye la posibilidad de trasformar el estado de cosas mediante los actos singulares y colectivos". Lo que define al nominalismo es su falta de aceptación de una realidad extralingüística, su sustitución de lo real por un acto de habla, sea este individual o colectivo, determinista o transformador. Y eso es justo lo que defiende Butler. Solo hay algo peor que sustituir lo real por una imputación lingüís- 
La disolución de todo referente ontológico propia de la teoría queer está a punto de conseguir su objetivo: llegará un momento en que no se pueda hablar de nada. Aquel en que la utilización de esquemas duales (sean o no dualistas), de sujetos y verbos, de modos adverbiales, de géneros y especies, en suma, de universales, se haga imposible por dejación de una minoría de teóricos, mientras la mayoría de las personas sigue construyendo con todas esas herramientas su experiencia cotidiana y sus luchas contra el sistema. Cuando todo se disuelva en el lenguaje, este se tornará inútil para entenderse y defenderse, ya que se extenderá como una piel sobre el mundo, como en el relato de Borges, pero no servirá como mapa de aquel: los mapas describen y representan. Sin un lenguaje que muestre otra cosa diferente del poder de quien lo maneja, si queremos comunicarnos habrá que llevar las cosas encima para señalarlas, como en la utopía de Swift. Ese día el totalitarismo neoliberal habrá triunfado definitivamente, pues el mundo se convertirá en un paisaje de cosas discretas, de individuos escindidos y ensimismados, de exciudadanos solo atentos al ¿qué hay de lo mío? Quizá haya que esperar a ese momento para intentar construir, con las modestas armas de la deliberación y el acuerdo, una auténtica filosofía política radical, apta para la resistencia, que tenga en cuenta dos de las lecciones que Lilla obtiene de la descomposición de la izquierda política: la prioridad de la persuasión democrática sobre la autoexpresión sin objeto y la de la ciudadanía sobre la identidad personal o de grupo (Lilla 2018, 112).

\section{REFERENCIAS BIBLIOGRÁFICAS}

Amorós, Celia. 1992. "Notas para una teoría nominalista del patriarcado”. Asparkía: Investigació feminista 1: 41-58.

Althusser, Louis. 2005. La filosofía como arma de la revolución: México: Siglo XXI.

tica: confundir uno y otra hasta no saber dónde se está, de qué se habla y el significado mismo del hecho de hablar. 
Bernabé, Daniel. 2018. La trampa de la diversidad. Cómo el neoliberalismo fragmentó la unidad de la clase trabajadora. Madrid: Akal.

Buss, D. M. 1995. "Psychological Sex Differences: Origins Through Sexual Selection". American Psychologist 50: 169- 171.

Butler, Judith. 2017. Cuerpos aliados y lucha politica. Hacia una teoría performativa de la asamblea. Barcelona: Paidós.

-. 2016. "El marxismo y lo meramente cultural". En ¿Reconocimiento o redistribución? Un debate entre marxismo y feminismo, Judith Butler, Nancy Fraser. Madrid: Traficantes de sueños: 67-87.

-. 2007. El género en disputa. El feminismo y la subversión de la identidad. Barcelona: Paidós.

-. 2002. Cuerpos que importan. Sobre los límites materiales y discursivos del "sexo". Buenos Aires: Paidós.

-. 1998. "Actos performativos y constitución del género: un ensayo de fenomenología y teoría feminista”. Debate feminista 18: 296-314.

Campagnoli, Mabel. 2015. "Dar cuenta de sí misma o la pregunta por una ética feminista". En Judith Butler, las identidades del sujeto opaco, coordinado por María Luisa Femenías y Ariel Martínez, 253273. Buenos Aires: Facultad de Humanidades y Ciencias de la Educación, Universidad Nacional de La Plata.

Colera, María. 2016. “Entrevista a Ángela Davis”. Diagonal 8 sept. 2016, consultado el 30 de noviembre de 2019 en https://www.elsaltodiario.com/ hemeroteca-diagonal/angela-davisraza-genero-y-clase-son-elementos-entrelazados.

Connellana, J. et al. 2000. "Sex differences in human neonatal social perception", Infant Behavior \& Development 23: 113-118.

De Santo, Magdalena. 2015. "Performances textuales en la obra temprana de Judith Butler”. En Judith Butler, las identidades del sujeto opaco, coordinado por María Luisa Femenías y Ariel Martínez, 2940. Buenos Aires: Facultad de Humanidades y Ciencias de la Educación, Universidad Nacional de La Plata.

Fraser, Nancy. 2016. “¿De la redistribución al reconocimiento? Dilemas de la justicia en la era «postsocialista»". En J. Butler et al., ¿Reconocimiento o redistribución? Un debate entre marxismo y feminismo, 23-66. Madrid: Traficantes de sueños. 
- "La justicia social en la era de la política de identidad: redistribución, reconocimiento y participación”. Revista de Trabajo 6: 83-99.

- "Heterosexismo, falta de reconocimiento y capitalismo: una respuesta a Judith Butler". New Left Review 2: 123-136.

Gómez, Juan Antonio. 2017. "Una fundamentación de los derechos humanos desde una hermenéutica analógica”. En J. M. Enríquez et al., Derechos humanos. Un análisis multidisciplinar de su teoría y praxis, 63-81. Madrid: UNED.

-. 2018. Derecho y analogía. Estudios de hermenéutica jurídica. Madrid: UNED.

González, Araceli. 2009. "Michel Foucault, Judith Butler, y los cuerpos e identidades críticas, subversivas y deconstructivas de la Intersexualidad". Isegoría 40: 235-244.

Ingalkhalikar, M. et al. 2014. "Sex differences in the structural connectome of the human brain". Proceedings of the National Academy of Sciences of the USA, 111: 823-828.

Kristol, Irving. 1995. Neoconservatism: The Autobiography of an Idea. New York: Free Press.

Lilla, Mark. 2018. El regreso liberal: más allá de la política de la identidad. Barcelona: Debate.

Lombardo, M. V. et al. 2012. "Fetal Testosterone Influences Sexually Dimorphic Gray Matter in the Human Brain". The Journal of Neuroscience 32: 674-680.

Mc Carthy, M. et al. 2012. "Sex Differences in the Brain: the not so inconvenient Truth". The Journal of Neuroscience 32: 2241-2247.

Mouffe, Chantal. 1999. El retorno de lo político. Comunidad, ciudadanía, pluralismo, democracia radical. Barcelona: Paidós.

-. 1996. "Feminismo, ciudadanía y política democrática radical". En Las Ciudadanas y lo político, coordinado por María Elena Beltrán et al., 1-20. Madrid: Universidad Autónoma de Madrid-Instituto Universitario de Estudios de la Mujer.

Muñoz de Baena, José Luis. 2018. La abstracción del mundo. Sobre el mal autoinmune de la juridicidad moderna. Madrid: CEPC. 
Ngun, T. C. 2011. "The Genetics of Sex Differences in Brain and Behavior”. Front Neuroendocrinology 32: 227-246.

Sacher, J. et al. 2013. "Sexual Dimorphism in the Human Brain: Evidence from Neuroimaging”. Magnetic Resonance Imaging 31: 366375 .

Sokal, Alan et al. 1999. Imposturas intelectuales. Barcelona: Paidós.

José Luis Muñoz de Baena Departamento de Filosofía Jurídica Universidad Nacional de Educación a Distancia Calle del Obispo Trejo, 2 28040 Madrid (España) jlmunozb@der.uned.es https://orcid.org/ooo-0o01-6728-9820 
